\title{
Desenvolvimento de mudas de pupunheira em Latossolo argiloso compactado artificialmente em subsuperfície
}

\author{
Peach palm seedlings development in artificiality subsurface compacted clayly Latossol
}

\author{
Ivan Bordin ${ }^{1}$ Robson Fernando Missio ${ }^{2}$ Evandro Luiz Nogarolli Casimiro ${ }^{2}$ \\ Ana Maria Conte e Castro ${ }^{3}{\text { Emerson } \mathrm{Fey}^{3}}^{3}$
}

\section{- NOTA -}

\section{RESUMO}

O trabalho teve como objetivo avaliar o desenvolvimento de mudas de pupunheira (Bactris gasipaes H.B.K.) cultivadas em amostras de um Latossolo Vermelho eutroférrico de textura argilosa compactado artificialmente em subsuperfície. As amostras de solo que foram compactadas a quatro níveis de densidade $\left(1,0 ; 1,13 ; 1,28\right.$ e $\left.1,44 \mathrm{~kg} \mathrm{dm}^{-3}\right)$ estavam nas camadas intermediárias de $3,5 \mathrm{~cm}$ de vasos de $P V C$ de $20 \mathrm{~cm}$ de diâmetro, que constavam de outras camadas superiores de $15 \mathrm{~cm}$ e inferiores de $10 \mathrm{~cm}$. As avaliações foram realizadas em quatro épocas (4, 6, 8 e 10 meses). $O$ aumento dos níveis de densidade do solo não influenciou no desenvolvimento da parte aérea das mudas de pupunheira. Independentemente da época estudada, os níveis de densidade do Latossolo argiloso não impediram a penetração das raízes da pupunheira.

Palavras-chave: sistema radicular, Bactris gasipaes, densidade do solo.

\section{ABSTRACT}

This study was carried out to evaluate the development of peach palm (Bactris gasipaes H.B.K.) seedlings submitted to artificiality subsurface compacted layers of a clayly texture eutroferric Red Latossol. The compacted soil was at the middle ring of the PVC pots. They were $20 \mathrm{~cm}$ of diameter, divided in tree rings with 15; 3,5 and $10 \mathrm{~cm}$ from the up side. The soil was submitted to four density levels $(1,0 ; 1,13 ; 1,28$ and $\left.1,44 \mathrm{~kg} \mathrm{dm}^{-3}\right)$, which determined the treatments. The evaluations were accomplished in four times (4, 6, 8 and 10 months). The increase of the soil density levels didn't influence in the development of the aerial part of the peach palm seedlings. Independent of the studied time, the clayly Latossol density levels, didn't prevent the peach palm roots penetration.

Key words: root system, Bactris gasipaes, soil density
As mobilizações intensivas do solo, sob condições inadequadas de umidade e de cobertura vegetal, modificam a estrutura física do solo. Desta forma, dividem a profundidade do solo explorada pelas plantas em camada arável pulverizada, superficial e camada compactada subsuperficial (DENARDIN \& KOCHHANN, 1997). Estas camadas subsuperficiais, quando sujeitas ao uso de máquinas cada vez maiores e pesadas para as operações de preparo do solo, podem levar a modificações na sua estrutura, agravando sua compactação, que poderá interferir na densidade do solo, na porosidade, na infiltração de água no solo e no desenvolvimento radicular das plantas e, conseqüentemente, na redução de seu crescimento e desenvolvimento (TAVARES FILHO et al., 2001). Segundo alguns autores, a densidade do solo, em torno de $1,5 \mathrm{~kg} \mathrm{dm}^{-3}$, é capaz de prejudicar o desenvolvimento de várias plantas cultivadas comercialmente (ALVARENGA et al., 1996; MULLER et al., 2001; SILVA \& ROSOLEM, 2001). Devido ao interesse crescente pela exploração da pupunheira (Bactris gasipaes H.B.K.), que oferece a possibilidade de ser cultivada a céu aberto em espaçamentos comerciais, abrangendo assim grandes áreas, com bom perfilhamento e precocidade para o primeiro corte em relação a outras palmeiras produtoras de palmito, como a juçara (Euterpe edulis) e açaí (Euterpe oleracea), o seu plantio vem ocorrendo em regiões de solos argilosos, condição esta diferente da encontrada em seu centro de origem naAmazônia (BONACCINI, 1997). O trabalho

\footnotetext{
${ }^{1}$ Universidade Estadual de Londrina (UEL). Autor para correspondência. Rua Heitor Ferrari Hablich, no 233, ap. 3, Centro. CEP 85660-000, Dois Vizinhos, PR, Brasil. E - mail: ivanbordin@uel.br

${ }^{2}$ Graduado pelaUNIOESTE, Marechal Cândido Rondon, PR, Brasil.

${ }^{3}$ Departamento de Agronomia, UNIOESTE, Marechal Cândido Rondon, PR, Brasil.
} 
teve o objetivo de estudar o comportamento de mudas de pupunheira cultivadas em Latossolo argiloso compactado artificialmente em subsuperfície, em casade-vegetação.

O experimento foi realizado sob telado com sombreamento de 50\%, no Núcleo de Estações Experimentais da Universidade Estadual do Oeste do Paraná (UNIOESTE), Campus de Marechal Cândido Rondon, no período de outubro de 2000 a agosto de 2001. O solo utilizado foi o Latossolo Vermelho eutroférrico coletado a uma profundidade de $0-30 \mathrm{~cm}$, com $703 \mathrm{~g} \mathrm{~kg}^{-1}$ de argila; $140 \mathrm{~g} \mathrm{~kg}^{-1}$ de areia e $157 \mathrm{~g} \mathrm{~kg}^{-1} \mathrm{de}$ silte, cuja análise química demonstrou: $20 \mathrm{~g} \mathrm{dm}^{-3} \mathrm{de}$ matéria orgânica; 6,4 de $\mathrm{pH} \mathrm{em} \mathrm{CaCl}_{2}\left(0,01 \mathrm{~mol} \mathrm{~L}^{-1}\right) ; 30 \mathrm{mg}$ $\mathrm{dm}^{-3}$ de P; $2,8 \mathrm{cmol}_{\mathrm{c}} \mathrm{dm}^{-3} \mathrm{de} \mathrm{K}^{+} ; 6,9 \mathrm{cmol}_{\mathrm{c}} \mathrm{dm}^{-3} \mathrm{de} \mathrm{Ca}^{2+}$; $1,1 \mathrm{cmol}_{\mathrm{c}} \mathrm{dm}^{-3} \mathrm{de}_{\mathrm{Mg}}^{2+} ; 2,81 \mathrm{cmol}_{\mathrm{c}} \mathrm{dm}^{-3} \mathrm{de} \mathrm{H}^{+}+\mathrm{Al}^{3+}$; $0,0 \mathrm{cmol}_{\mathrm{c}} \mathrm{dm}^{-3} \mathrm{de} \mathrm{Al}^{3+} ; 8,63 \mathrm{cmol}_{\mathrm{c}} \mathrm{dm}^{-3} \mathrm{de} \mathrm{SB} ; 11,4 \mathrm{cmol}_{\mathrm{c}}$ $\mathrm{dm}^{-3}$ de CTC e 74 de V \%. Foram confeccionados vasos de $20 \mathrm{~cm}$ de diâmetro e $28,5 \mathrm{~cm}$ de altura, utilizando-se tubos de PVC divididos em três camadas sobrepostas, respectivamente do topo para a base, de $15 ; 3,5$ e $10 \mathrm{~cm}$, preenchidos com solo peneirado em malha de $1 \mathrm{~cm}$. A camada superior de $15 \mathrm{~cm}$ foi preenchida com proporções de $75 \%$ de solo solto e $25 \%$ de composto de lixo urbano, que continha $2,3 \mathrm{~g} \mathrm{~kg}^{-1}$ de $\mathrm{P}_{2} \mathrm{O}_{5} ; 11,4 \mathrm{~g}$ $\mathrm{kg}^{-1}$ de $\mathrm{K}_{2} \mathrm{O} ; 43,8 \mathrm{~g} \mathrm{~kg}^{-1}$ de $\mathrm{Ca}^{2+} ; 2,68 \mathrm{~g} \mathrm{~kg}^{-1}$ de $\mathrm{Mg}^{2+}$, ficando esta composição com características semelhantes às utilizadas na região pelos agricultores para o preenchimento dos sacos plásticos (de $15 \times 10 \mathrm{~cm}$ ) durante o período de muda desta espécie, enquanto que o solo da camada intermediária $(3,5 \mathrm{~cm})$ recebeu quatro níveis de densidade $\left(1,0 ; 1,13 ; 1,28 \mathrm{e} 1,44 \mathrm{~kg} \mathrm{dm}^{-3}\right)$. Para isso, o solo teve sua umidade previamente padronizada a $0,32 \mathrm{~kg} \mathrm{~kg}^{-1}$, determinada por um ensaio preliminar como sendo a umidade que proporcionava a máxima compactação do solo. A compactação da camada de $3,5 \mathrm{~cm}$ foi realizada utilizando-se um cilindro de madeira com diâmetro ligeiramente inferior ao das camadas, que recebeu pancadas de um bloco de concreto de $7,2 \mathrm{~kg}$, suspenso manualmente por uma haste de ferro. O número de pancadas foi o necessário para acomodar uma massa conhecida de solo em uma camada de PVC de volume conhecido, proporcionando as densidades desejadas. A camada inferior de $10 \mathrm{~cm}$ foi preenchida com solo com a densidade padronizada de $1,0 \mathrm{~kg} \mathrm{dm}^{-3}$. Antes da montagem dos vasos, foi colocada uma fita adesiva na borda das camadas compactadas e dobrada para dentro, formando uma aba perpendicular à superfície interna da camada compactada, com a finalidade de não permitir a passagem de raízes entre o solo e a parede do vaso.

Depois da montagem dos vasos, foram plantadas mudas de pupunheira, com dois meses de idade, oriundas da floresta amazônica peruana. As plântulas tinham em média $15,9 \mathrm{~cm}$ de altura apresentando várias radicelas e bom estado fitossanitário. Após o plantio das mudas nos vasos, os mesmos foram pesados diariamente, durante um período de 30 dias, obtendo-se, assim, a referência para manutenção da umidade $(70 \%$ da capacidade de campo), durante o experimento. As irrigações foram realizadas em intervalos de três dias, pela superfície dos vasos. As variáveis avaliadas referentes à parte aérea foram: altura de planta $(\mathrm{cm})$, medida com trena até a ponta da folha mais alta; diâmetro do caule $(\mathrm{cm})$, por meio de paquímetro digital; área foliar $\left(\mathrm{cm}^{2}\right)$, medida com auxílio do scanner de área Meter modelo 100; matéria seca $(\mathrm{g})$, sendo a parte aérea separada do sistema radicular e levada para secar em estufa a $65^{\circ} \mathrm{C}$ por 48 horas. Para obtenção das variáveis radiculares, as amostras de solo de cada camada foram lavadas com jatos de água de torneira sobre peneira com malha de $1 \mathrm{~mm}$. As raízes foram submetidas à leitura ótica com scanner e analisadas pelo programa "Win Mac Rhizo" v. 3.8 para obtenção do comprimento $(\mathrm{cm})$, diâmetro $(\mathrm{cm})$ e área $\left(\mathrm{cm}^{2}\right)$. O delineamento experimental utilizado foi o inteiramente casualizado em esquema de parcelas subdivididas. As parcelas foram as densidades do solo, e as sub-parcelas foram as épocas amostradas, constando de quatro repetições por tratamento. Os dados foram submetidos à análise de variância e ao teste de Tukey a 5\% de significância pelo programa estatístico Sisvar.

Para o desenvolvimento da parte aérea (Tabela 1), não ocorreu o efeito de interação entre as densidades do solo e as épocas avaliadas. Para as densidades do solo, observa-se que não houve diferenças estatísticas para a altura, diâmetro do caule, área foliar e massa seca. Em trabalho semelhante, ALVARENGAet al. (1996), ao trabalharem com a espécie mata-pasto (Senna ocidentalis L.), observaram a não existência da interferência da compactação do solo sobre a parte aérea desta espécie, enquanto para feijãode-porco (Canavalia ensiformes L.) e feijão-bravo-doceará (Canavalia brasiliensis M.), houve diminuição no crescimento de sua parte aérea. No trabalho realizado por MÜLLER et al. (2001), foi constatado o incremento de valores referentes à parte aérea, quando eram aumentados os níveis de compactação do solo, ao trabalharem com tremoço branco (Lupinus albus L.). As respostas da parte aérea das plantas à compactação do solo são controversas, devido provavelmente à deficiência de água e nutrientes, assim, numa condição de vasos, onde o fornecimento de água e nutrientes não são limitantes, seus efeitos podem não ser os esperados (SILVA\& ROSOLEM, 2001). Para as épocas estudadas referentes à parte aérea (Tabela 1), houve diferenças crescentes para o diâmetro do caule durante todo período amostrado, enquanto este fato não foi constatado para a altura, área foliar e mtéria seca, que 
tiveram seus valores aos 8 e 10 meses superiores aos de 6 e 4 meses.

Quanto ao crescimento do sistema radicular na camada acima da camada compactada (Tabela 1), também não ocorreu interação entre as densidades do solo e épocas avaliadas. Não houve diferenças para o comprimento, área e diâmetro das raízes avaliados nas diferentes compactações de solo, contrariando as respostas encontradas por outros autores ao avaliarem várias espécies de plantas utilizadas como adubos verdes (MULLER et al., 2001 ; SILVA \& ROSOLEM, 2001). Esta falta de respostas pode ser atribuída às características desta camada, a qual recebeu $25 \%$ de sua proporção com composto orgânico, onde a irrigação não foi um fator limitante, juntamente com o fato de o sistema radicular da pupunheira ser fasciculado e superficial (BORDIN et al., 2001). Para as épocas referentes ao sistema radicular na camada acima da camada compactada, não houve diferenças para o comprimento de raízes. No entanto, a área e o diâmetro radicular foram superiores aos de 8 meses em relação aos de 4 meses, não se diferenciando das demais épocas.

Pode-se notar que, na camada compactada (Tabela 2), a falta de interação entre as densidades do solo e épocas amostradas ocorreu para o diâmetro de raízes, enquanto esta interação foi constatada para o comprimento e área radiculares. Para o diâmetro das raízes, não foi observada diferença em relação às densidades do solo. Este resultado está de acordo com os resultados encontrados por SILVA \& ROSOLEM (2001) e MULLER et al. (2001) que, ao estudarem várias espécies de plantas utilizadas como adubos verdes com diferentes hábitos de crescimento radicular, constataram que, em algumas espécies, não houve aumento do diâmetro de raízes à medida que se aumentava o nível de compactação do solo. Em relação às épocas amostradas, as medidas do diâmetro radicular aumentaram nas três últimas épocas em relação à primeira. Respostas semelhantes para o comprimento e área radicular foram encontradas (Tabela 2), sendo os menores valores nas densidades do solo de $1,28 \mathrm{~kg}$ $\mathrm{dm}^{-3}$ e $1,44 \mathrm{~kg} \mathrm{dm}^{-3}$ em relação às demais densidades aos 8 meses e em $1,44 \mathrm{~kg} \mathrm{dm}^{-3}$ em relação a $1,0 \mathrm{~kg} \mathrm{dm}^{-3}$, não se diferenciando das demais densidades aos 10 meses. Apesar da limitação imposta pelas camadas de solo compactadas ao desenvolvimento radicular da pupunheira, as mesmas não foram capazes de impedir a penetração das raízes. Como o sistema radicular das plantas de pupunha é do tipo fasciculado, composto por raízes relativamente grossas (MORALES \& VARGAS, 1990), pode-se atribuir a pressão exercida pelas raízes sobre a camada compactada como a principal justificativa para superação deste impedimento físico.

Não houve diferença para as variáveis radiculares avaliadas na camada abaixo daquela compactada, tanto para as densidades do solo quanto para as épocas. Esta falta de resposta está relacionada à pequena quantidade de raízes que chegaram a esta última camada (sem compactação) e pode ser atribuída ao fato de as raízes não conseguirem se recuperar do estresse ao qual foram submetidas, gastando maior quantidade de fotoassimilados para passarem pelo impedimento físico (MASLE \& FARQUHAR, 1988). Pode-se concluir que o aumento dos níveis de densidade do solo não influenciou no desenvolvimento da parte aérea das mudas de pupunheira e

Tabela 1 - Altura, diâmetro do caule, área foliar, matéria seca da parte aérea e comprimento de raízes, área de raízes, diâmetro de raízes de mudas de pupunheira referentes à parte aérea e à camada acima da camada compactada em relação as densidades do solo (parcelas) e épocas amostradas (sub-parcelas).

\begin{tabular}{|c|c|c|c|c|c|c|c|}
\hline $\begin{array}{c}\text { Parcelas e } \\
\text { subparcelas }\end{array}$ & Altura $(\mathrm{cm})$ & $\begin{array}{c}\text { Diâmetro do } \\
\text { caule }(\mathrm{cm})\end{array}$ & $\begin{array}{l}\text { Área foliar } \\
\left(\mathrm{cm}^{2}\right)\end{array}$ & $\begin{array}{c}\text { Matéria seca } \\
(\mathrm{g})\end{array}$ & $\begin{array}{l}\text { Comprimento } \\
\text { de raízes }(\mathrm{cm})\end{array}$ & $\begin{array}{l}\text { Área de raízes } \\
\qquad\left(\mathrm{cm}^{2}\right)\end{array}$ & $\begin{array}{c}\text { Diâmetro de } \\
\text { raízes }(\mathrm{cm})\end{array}$ \\
\hline & \multicolumn{4}{|c|}{ Parte aérea } & \multicolumn{3}{|c|}{ Camada acima da camada compactada } \\
\hline & \multicolumn{7}{|c|}{ Densidade do solo $\left(\mathrm{kg} \mathrm{dm}^{-3}\right)$} \\
\hline 1,00 & $45,54 a^{*}$ & $0,84 \mathrm{a}$ & $286,40 \mathrm{a}$ & $5,17 \mathrm{a}$ & $419,50 \mathrm{a}$ & $209,20 \mathrm{a}$ & $0,16 \mathrm{a}$ \\
\hline 1,13 & $44,43 a$ & $0,84 \mathrm{a}$ & $331,60 \mathrm{a}$ & $5,21 \mathrm{a}$ & $478,20 \mathrm{a}$ & $241,10 \mathrm{a}$ & $0,20 \mathrm{a}$ \\
\hline 1,28 & $49,37 \mathrm{a}$ & $0,94 \mathrm{a}$ & $377,80 \mathrm{a}$ & $6,02 \mathrm{a}$ & $527,30 \mathrm{a}$ & $286,70 \mathrm{a}$ & $0,16 \mathrm{a}$ \\
\hline 1,44 & $44,14 \mathrm{a}$ & $0,84 \mathrm{a}$ & $284,10 \mathrm{a}$ & $4,61 \mathrm{a}$ & $484,40 \mathrm{a}$ & $238,10 \mathrm{a}$ & $0,16 \mathrm{a}$ \\
\hline \multirow[t]{2}{*}{$\mathrm{CV} \%$} & 36,20 & 37,96 & 46,48 & 45,1 & 40,79 & 48,39 & 46,45 \\
\hline & \multicolumn{7}{|c|}{ Épocas (meses) } \\
\hline 4 & $36,92 \mathrm{c}$ & $0,34 \mathrm{~d}$ & $262,70 b$ & $2,39 b$ & $398,30 \mathrm{a}$ & $163,90 \mathrm{~b}$ & $0,14 b$ \\
\hline 6 & $40,28 b c$ & $0,72 \mathrm{c}$ & $232,00 \mathrm{~b}$ & $3,95 b$ & $487,60 \mathrm{a}$ & $228,40 \mathrm{ab}$ & $0,15 \mathrm{ab}$ \\
\hline 8 & $50,27 \mathrm{a}$ & $1,11 \mathrm{~b}$ & $398,20 \mathrm{a}$ & $6,70 \mathrm{a}$ & $564,70 \mathrm{a}$ & $343,60 \mathrm{a}$ & $0,23 \mathrm{a}$ \\
\hline 10 & $58,38 \mathrm{a}$ & $1,38 \mathrm{a}$ & $478,70 \mathrm{a}$ & $8,56 \mathrm{a}$ & $470,80 \mathrm{a}$ & $254,90 \mathrm{ab}$ & $0,17 \mathrm{ab}$ \\
\hline $\mathrm{CV} \%$ & 25,23 & 22,44 & 39,87 & 35,02 & 40,85 & 51,10 & 50,75 \\
\hline
\end{tabular}

*Médias seguidas da mesma letra, na coluna, não diferem pelo teste de Tukey a 5\% de probabilidade de erro.

Ciência Rural, v.36, n.1, jan-fev, 2006. 
Tabela 2 - Diâmetro de raízes, área de raízes e comprimento de raízes de mudas de pupunheira referentes a camada de solo compactada, em função das densidades do solo (parcelas) e épocas amostradas (sub-parcelas).

\begin{tabular}{|c|c|c|c|c|c|}
\hline \multirow{2}{*}{ Densidade do solo $\left(\mathrm{kg} \mathrm{dm}^{-3}\right)$} & \multicolumn{5}{|c|}{ Épocas (meses) } \\
\hline & 4 & 6 & 8 & 10 & Média \\
\hline \multicolumn{6}{|c|}{ Diâmetro de raízes $(\mathrm{cm})$} \\
\hline 1,00 & 0,02 & 0,08 & 0,10 & 0,11 & $0,08 \mathrm{~A}$ \\
\hline 1,13 & 0,03 & 0,12 & 0,10 & 0,12 & $0,09 \mathrm{~A}$ \\
\hline 1,28 & 0,01 & 0,11 & 0,11 & 0,05 & $0,07 \mathrm{~A}$ \\
\hline 1,44 & 0,01 & 0,5 & 0,4 & 0,7 & $0,04 \mathrm{~A}$ \\
\hline Média & $0,02 b^{*}$ & $0,09 \mathrm{a}$ & $0,09 \mathrm{a}$ & $0,09 \mathrm{a}$ & \\
\hline $\mathrm{CV} \%$ & Densidades & 103,90 & Épocas & 67,01 & \\
\hline \multicolumn{6}{|c|}{ Área de raízes $\left(\mathrm{cm}^{2}\right)$} \\
\hline 1,00 & $4,06 \mathrm{Ab}$ & $18,79 \mathrm{Aab}$ & $26,15 \mathrm{Aa}$ & $24,46 \mathrm{Aa}$ & 18,36 \\
\hline 1,13 & $0,00 \mathrm{Ab}$ & $7,48 \mathrm{Ab}$ & $35,53 \mathrm{Aa}$ & $18,25 \mathrm{ABab}$ & 15,31 \\
\hline 1,28 & $1,67 \mathrm{Aa}$ & 7,33Aa & $4,55 \mathrm{Ba}$ & $10,38 \mathrm{ABba}$ & 5,98 \\
\hline 1,44 & $0,00 \mathrm{Aa}$ & $3,49 \mathrm{Aa}$ & $2,54 \mathrm{Ba}$ & $1,67 \mathrm{Ba}$ & 1,92 \\
\hline Média & 1,43 & 9,27 & 17,19 & 13,69 & \\
\hline $\mathrm{CV} \%$ & Densidades & 86,33 & Épocas & 79,88 & \\
\hline \multicolumn{6}{|c|}{ Comprimento de raízes $(\mathrm{cm})$} \\
\hline 1,00 & $10,58 \mathrm{Ab}$ & $55,89 \mathrm{Aab}$ & $77,14 \mathrm{Aa}$ & $69,68 \mathrm{Aa}$ & 53,32 \\
\hline 1,13 & $0,00 \mathrm{Ab}$ & $17,45 \mathrm{Ab}$ & $88,95 \mathrm{Aa}$ & $44,15 \mathrm{ABab}$ & 37,63 \\
\hline 1,28 & $3,72 \mathrm{Aa}$ & $21,11 \mathrm{Aa}$ & $11,95 \mathrm{Ba}$ & $28,24 \mathrm{ABa}$ & 32,24 \\
\hline 1,44 & $0,00 \mathrm{Aa}$ & $9,15 \mathrm{Aa}$ & $5,85 \mathrm{Ba}$ & $2,95 \mathrm{Ba}$ & 4,48 \\
\hline Média & 3,57 & 25,9 & 45,97 & 36,25 & \\
\hline $\mathrm{CV} \%$ & Densidades & 72,42 & Épocas & 84,93 & \\
\hline
\end{tabular}

*Médias, seguidas da mesma letra maiúscula, na coluna, e minúscula, na linha, não diferem pelo teste de Tukey a 5\% de probabilidade de erro.

independentemente da época estudada, os níveis de densidade do Latossolo argiloso não impediram a penetração das raízes da pupunheira.

\section{AGRADECIMENTOS E APRESENTAÇÃO}

Ao Programa Institucional de Bolsas de Iniciação Científica / Universidade Estadual do Oeste do Paraná (PIBIC/ UNIOESTE) pelo financiamento do trabalho de conclusão do curso na UNIOESTE.

Trabalho de Conclusão de Curso apresentado à Universidade Estadual do Oeste do Paraná (UNIOESTE), Marechal Cândido Rondon, PR, Brasil.

\section{REFERÊNCIAS}

ALVARENGA, R.C. et al. Crescimento de raízes de leguminosas em camadas de solo compactadas artificialmente. Revista Brasileira de Ciência do Solo, Campinas, v.20, n.2, p.319326, 1996.

BONACCINI, L.A. Produza palmito: a cultura da pupunha Cuiabá: SEBRAE, 1997. 96p.

BORDIN, I. et al. Distribuição e interação do sistema radicular da pupunheira no perfil de um Latossolo Vermelho eutroférico. Scientia Agrária Paranaensis, Cascavel, v.1, n.1, p.43-54, 2001 .
DENARDIN. J.E.; KOCHHANN, R.A. Pesquisa de desenvolvimento em sistema plantio direto no Rio Grande do Sul, Rio de Janeiro, RJ, 1997. In: CONGRESSO BRASILEIRO DE CIÊNCIA DO SOLO, 26., Rio de Janeiro, RJ. Anais... Rio de Janeiro: Sociedade Brasileira de Ciência do Solo, 1997. CDROM.

MASLE, J.; FARQUHAR, G.D. Effects of soil strenght on the relation of water-use efficiency and growth to carbon isotope discrimination in wheat seedlings. Plant Physiology, Massachusetts, v.86, n.1, p.32-38, 1988.

MORALES, A.L.; VARGAS, H.S. Observaciones sobre la distribución radial del pejibaye (Bactris gasipaes H. B. K.) para palmito en un andosol. Revista de la Asociación Bananera Nacional, São Luiz, v.14, n.34, p.9-15, 1990.

MÜLLER, M.M.L. et al. Influência da compactação do solo em subsuperfície sobre o crescimento aéreo e radicular de plantas de adubação verde de inverno. Revista Brasileira de Ciência do Solo, Viçosa, v.25, n.3, p.531-538, 2001.

SILVA, H.R.; ROSOLEM, C.A. Crescimento radicular de espécies utilizadas como cobertura decorrente da compactação do solo. Revista Brasileira de Ciência do Solo, Viçosa, v. 25, n. 2 , p. $253-260,2001$

TAVARES FILHO, J. et al. Resistência do solo à penetração e desenvolvimento do sistema radicular do milho (Zea mays) sob diferentes sistemas de manejo em um Latossolo Roxo. Revista Brasileira de Ciência do Solo, Viçosa, v.25, n.3, p.725730, 2001 .

Ciência Rural, v.36, n.1, jan-fev, 2006. 